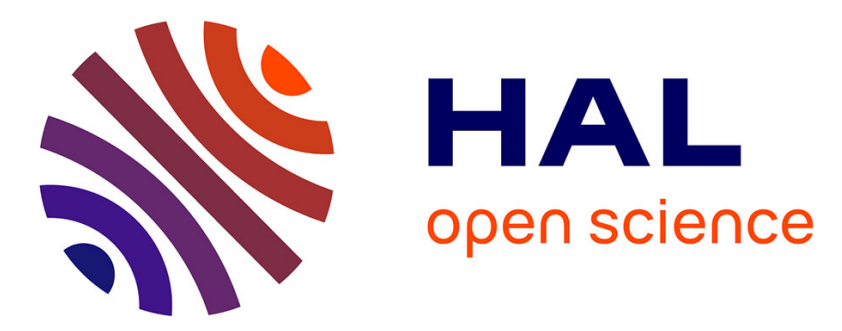

\title{
Inherited state of stress as a key factor controlling slip and slip mode: inference from the study of a slow slip event in the Longitudinal Valley, Taiwan
}

\author{
Alexandre Canitano, Maxime Godano, Marion Y. Thomas
}

\section{To cite this version:}

Alexandre Canitano, Maxime Godano, Marion Y. Thomas. Inherited state of stress as a key factor controlling slip and slip mode: inference from the study of a slow slip event in the Longitudinal Valley, Taiwan. Geophysical Research Letters, 2021, 48 (3), pp.e2020GL090278. 10.1029/2020GL090278 . hal-03083654

\section{HAL Id: hal-03083654 https://hal.science/hal-03083654}

Submitted on 19 Dec 2020

HAL is a multi-disciplinary open access archive for the deposit and dissemination of scientific research documents, whether they are published or not. The documents may come from teaching and research institutions in France or abroad, or from public or private research centers.
L'archive ouverte pluridisciplinaire HAL, est destinée au dépôt et à la diffusion de documents scientifiques de niveau recherche, publiés ou non, émanant des établissements d'enseignement et de recherche français ou étrangers, des laboratoires publics ou privés. 


\section{Inherited state of stress as a key factor controlling slip and slip mode: inference from the study of a slow slip event in the Longitudinal Valley, Taiwan}

Alexandre Canitano ${ }^{1}$, Maxime Godano ${ }^{2}$ and Marion Y. Thomas ${ }^{3}$

Corresponding author: A. Canitano, Institute of Earth Sciences, Academia Sinica, Nankang, Taipei, Taiwan. (canitano@earth.sinica.edu.tw)

${ }^{1}$ Institute of Earth Sciences, Academia

Sinica, Nankang, Taipei, Taiwan.

${ }^{2}$ Université Côte d'Azur, CNRS,

Observatoire de la Côte d'Azur, IRD,

Géoazur, 250 rue Albert Einstein, Sophia

Antipolis 06560 Valbonne, France.

${ }^{3}$ Sorbonne Université, CNRS-INSU,

Institut des Sciences de la Terre Paris,

ISTeP UMR 7193, F-75005 Paris, France.

D R A F T

November 6, 2020, 11:55am

D R A F T 
${ }_{4} \quad$ Using borehole strainmeters, we detected a 13-day long slow slip event in ${ }_{5} 2011$ with $M_{w}=5.45$ on the Longitudinal Valley Fault, Taiwan. It has been

${ }_{6}$ likely promoted by the significant Coulomb stress changes $(\sim 0.5-1 \mathrm{MPa})$ im-

7 parted by a combination of coseismic and postseismic slip of the 2003 Chengkung

s earthquake. Using kinematic slip models, we infer that the slow event has

9 accomodated about 15 to $35 \%$ of the slip deficit accumulated in 2011 in its

${ }_{10}$ source region. Further, we find that inherited state of stress may have con-

${ }_{11}$ trolled the slow event southward propagation. We also highlight a spatiotem-

${ }_{12}$ poral correlation between the slow event and a cluster of repeating microearthquakes,

${ }_{13}$ suggesting a complex interplay between seismic and aseismic processes on

${ }_{14}$ the fault, where transient aseismic regions are adjacent to highly coupled zones. 


\section{Introduction}

Over the last two decades, the growing development of geodetic and seismological mon-

${ }_{16}$ itoring arrays in active regions has revealed episodic aseismic slip in the crust, spanning

${ }_{17}$ timescales from seconds to years [e.g., Peng and Gomberg, 2010]. These slow slip events

${ }_{18}$ (SSEs) play an important role in redistributing stress in the Earth's crust [e.g., Linde

19 et al., 1996] and are now observed in various tectonic regions [e.g., Bürgmann, 2018].

${ }_{20}$ SSEs are often accompanied by earthquake swarms [Vallée et al., 2013; Gualandi et al.,

${ }_{21}$ 2017; Fasola et al., 2019] or nonvolcanic tremors [e.g., Beroza and Ide, 2011], and together,

22 represent an important mechanism of strain release in active regions. Therefore, investi-

23 gating the stress conditions, the faulting mechanisms of slow slip and what role they play

${ }_{24}$ in the earthquake cycle is fundamental to determine time-dependent earthquake hazard.

${ }_{26}$ In eastern Taiwan, the Longitudinal Valley (LV) is an active collision boundary be${ }_{27}$ tween the Eurasian and Philippine Sea plates [Barrier and Angelier, 1986], and accounts ${ }_{28}$ for more than half of the $9 \mathrm{~cm} \cdot \mathrm{yr}^{-1}$ of oblique plate convergence [Yu et al., 1997]. The

${ }_{29}$ Longitudinal Valley Fault (LVF), which runs along the eastern side of the LV, represents

30 the major active structure in the region and accounts for about $4.5 \mathrm{~cm} \cdot \mathrm{yr}^{-1}$ of total plate ${ }_{31}$ convergence [Thomas et al., 2014a] (Figure 1). The fault is creeping at the surface at ${ }_{32}$ the rate of $1-6 \mathrm{~cm} / \mathrm{yr}$ between latitudes $23^{\circ} 00^{\prime}$ and $23^{\circ} 30^{\prime}$ [Thomas et al., 2014a] and also 3з experiences seasonal and transient creep episodes [Lee et al., 2003; Murase et al., 2013].

${ }_{34}$ Despite significant historical earthquakes, there is a paucity of large shocks along the 35 fault relatively to the high convergence rate, suggesting that a significant fraction of the 
${ }_{36}$ long-term slip rate, in the seismogenic depth range, is released aseismically [Liu et al.,

${ }_{37}$ 2009]. Indeed, based on the analysis of geodetic data for the 1992-2010 period, Thomas

${ }_{38}$ et al. [2014a] demonstrate that 80 to $90 \%$ of the long-term slip budget on the southern

39 section of the LVF is the result of aseismic slip. Following the $2003 M_{w} 6.8$ Chengkung

40 earthquake, a 7-year long afterslip has been detected by Global Positioning System (GPS)

${ }_{41}$ stations along the Chihshang Fault (CF) [Thomas et al., 2014a], a 30-km long section of

42 the southern LVF. Borehole strainmeters have captured a very shallow SSE (2 to $4 \mathrm{~km}$

${ }_{43}$ depth) with geodetic moment magnitude $M_{w} \sim 4.5$ in central LV [Canitano et al., 2019].

${ }_{44}$ A 1-month long afterslip following a $M_{w} 4.6$ earthquake on the CF was also shown to

${ }_{45}$ control the rate of aftershocks near the earthquake source region [Canitano et al., 2018a].

${ }_{46}$ However, the dearth of aseismic transient observations in the region strongly limits our

${ }_{47}$ ability to investigate the mechanisms of slow deformation along the fault and to further

${ }_{48}$ interpret the interplay between seismic and aseismic processes.

49

50 In this study, we document a 2-week long SSE with an equivalent moment magnitude of

${ }_{51}$ 5.45. It occurred in January-February 2011 on the central section of the LVF, northeast

${ }_{52}$ of the source rupture of the 2003 Chengkung earthquake. This event occurred between

53 about 8 to $14 \mathrm{~km}$ depth and was detected by borehole strainmeters deployed in two net-

${ }_{54}$ works distant by $35 \mathrm{~km}$. Using static Coulomb stress modeling, we investigate a possible

${ }_{55}$ contribution of coseismic and postseismic slip of the Chengkung event to the SSE occur-

${ }_{56}$ rence. We also analyze the spatiotemporal pattern of a cluster of earthquake multiplets

${ }_{57}$ occurring during the SSE episode and investigate its relationship with aseismic slip. Fi- 
${ }_{58}$ nally, we investigate the behaviour of the SSE region during the Chengkung earthquake

${ }_{59}$ and discuss the SSE contribution to the release of slip deficit along the LVF.

\section{Near-fault instrumentation and data processing}

Beginning in 2003, to shed additional light on the nature of the deformation in the

${ }_{62}$ LV, the Institute of Earth Sciences (IES) Academia Sinica, in cooperation with the De-

${ }_{63}$ partment of Terrestrial Magnetism, Carnegie Institution of Washington, has deployed 11

${ }_{64}$ Sacks-Evertson [Sacks et al., 1971] borehole strainmeters along the LVF (Figure 1). They

${ }_{65}$ monitor rock volume change (dilatation $\epsilon_{v}$ ) and complement the GPS measurements for

${ }_{66}$ detecting crustal transients at short to intermediate periods (minutes to weeks). We cali-

${ }_{67}$ brate the dilatometers using solid-Earth and ocean tides [Canitano et al., 2018b] (Figure

${ }_{68} \mathrm{~S} 1$ ), and correct the strain data for borehole relaxation, for solid-Earth and ocean tidal

${ }_{69}$ strain and air pressure induced strain. To monitor strain changes caused by hydrological

70 variations, rainfall and groundwater level stations were deployed by the Central Weather

${ }_{71}$ Bureau (CWB) and the Water Resources Bureau in Taiwan, respectively. Sea level changes

72 are continuously monitored by a tide gauge installed near Chengkung and operated by

${ }_{73}$ the CWB. The corrected strain signals and environmental signals are presented in Figure

${ }_{74}$ 2. We process the GPS data (Figure 1b) with the GAMIT10.42/GLOBK5.16 software

75 packages [Herring et al., 2010] using the 2005 International Terrestrial Reference Frame

76 (ITRF2005) [Altamini et al., 2007] coordinates in GLOBK processing (Figure S2). 


\section{Detection and characterization of the SSE}

${ }_{78}$ Volumetric strain response to rainfall represents the largest signal observed in strain79 meter time-series. Hours to days following the rainfall, a contraction signal proportional

so to the amount of cumulative rainfall is recorded (Figure S3a). A rainfall-strain admittance ${ }_{81}$ of $-0.51 \mathrm{n} \epsilon / \mathrm{mm}$ is found for the central LV [Hsu et al., 2015]. At longer periods (weeks to 82 months), an alternance of phases of contraction and expansion is observed, which suggests 83 that volumetric crustal strain is likely modulated by the cumulative rainfall loading (Fig${ }_{84}$ ure S3b). Such deformation is complex, highly site-dependent (e.g., local topography, rock ${ }_{85}$ elastic/poroelastic properties) [Mouyen et al., 2017], and its mechanisms remain poorly ${ }_{86}$ constrained in the region.

87

${ }_{88} \quad$ Starting on 29 January 2011 (day 29), we observe an expansion of +50 nanostrain ${ }_{89}(\mathrm{n} \epsilon)$ at SSTB station, synchronous with a contraction of $-39 \mathrm{n} \epsilon$ at ZANB station and 90 a moderate contraction $(\sim-10 \mathrm{n} \epsilon)$ at HGSB station (Figure 2a). FBRB do not record ${ }_{91}$ any relevant signal (SSNB and CHMB experience a power outage). On day 28.2, a light 92 rainfall episode (12 mm of rainfall within 12 hours) (Figures $2 \mathrm{~b}$ and $\mathrm{S} 4$ ) occurs in the CR 93 (Figure 1b, station C0T9M0 near ZANB) inducing a contraction of $-7 \mathrm{n} \epsilon$ at ZANB, which ${ }_{94}$ is about the value expected based on the rainfall-strain admittance in the region [Hsu ${ }_{95}$ et al., 2015]. Rainfall has likely stopped when SSTB signal initiates its large expansion ${ }_{96}$ (Figure S4a), that is unlikely to be the strain response to rainfall. Besides, to produce ${ }_{97}$ the contraction detected by ZANB and HGSB (-39 n $\epsilon$ and -10 n $\epsilon$, respectively), it would 98 require continuous rainfall from days 29 to 42 with an amount of $\sim 80 \mathrm{~mm}$ and of $20 \mathrm{~mm}$ 
99 of water, respectively, which is not observed (Figure S4b). Therefore, strain variations are

105

not associated with precipitation and neither are they induced by hydrology as no transient change in groundwater level is detected during January-February 2011 (Figure 2b).

There are also no appreciable sea level changes, the largest variations occurring during day $34(\sim 0.1 \mathrm{~m})$ and remain undetected by near-coastal stations (Figure $2 \mathrm{c})$. Finally, no signal is detected by the GPS stations (Figure S2).

Strain signals with nearly similar temporal evolution are detected from days 29 to 41.8 in two networks distant by $35 \mathrm{~km}$ (Figure 2d). They are unrelated to environmental changes and represent unambiguous evidence for a slow slip episode. Signals follow a logarithmic time-dependence, a pattern observed on borehole strainmeters during a previous SSE [Canitano et al., 2019]. Additionally, following day 41.8, ZANB records a moderate expansion $(+20 \mathrm{n} \epsilon)$ during 3 days (Figure 2a), while a contraction of $\sim-5 \mathrm{n} \epsilon$ is expected due to $10 \mathrm{~mm}$ of cumulative rainfall (Figure S4, station C0T9M0). HGSB records a contraction of $-10 \mathrm{n} \epsilon$ that is about 5 times larger than the expected changes due to $3-4 \mathrm{~mm}$ of rainfall (Figure S4, station C0Z070), while FBRB do not record any variation. Since these variations are unrelated to environmental perturbations or to sensor drift or relaxation, they may be the signature of a propagating source [e.g., Linde et al., 1996]. However, it remains difficult to characterize this possible second slow phase because of the lack of data (no signal for SSTB), which limits our ability to fully decipher the complexity of this event. Consequently, we only characterize the 13-day long main phase and thus estimate 
${ }_{120}$ a minimum moment magnitude for the sequence.

${ }_{122}$ We search for a source compatible with the LVF ( strike $=23^{\circ} \mathrm{NE}$ ) and a geologic rake ${ }_{123}$ of $70^{\circ}$, which corresponds to the mean slip vector direction in the Yuli-Fuli region [Peyret ${ }_{124}$ et al., 2011]. We estimate the optimal source location and magnitude for a rectangular 125 fault with uniform slip embedded in an elastic homogeneous half-space [Okada, 1992] with 126 a rigidity $G=30 \mathrm{GPa}$ using a grid search approach derived from GPS source modeling ${ }_{127}$ [Lin et al., 2019] (Section S1 and Figure S5). A minimum misfit is achieved ( $\mathrm{rms}<1$ ${ }_{128} \mathrm{n} \epsilon$ ) for a source with length of $L=16-24 \mathrm{~km}$, width of $W=3.8-12 \mathrm{~km}$ and aseismic ${ }_{129}$ slip of $U=2-10 \mathrm{~cm}$ at the depth of $10.5-11.5 \mathrm{~km}$. The fault surface is constrained in ${ }_{130}$ the range $65-288 \mathrm{~km}^{2}$, the source aspect ratio $(L / W)$ is ranging from 1.8 to 4.6 and the ${ }_{131}$ geodetic moment magnitude $M_{w}=5.41-5.45$ (Figure S6a). Our preferred source model ${ }_{132}(\mathrm{rms}$ misfit $=0.36 \mathrm{n} \epsilon)$ is located at $10.75 \mathrm{~km}$ depth, it has length and width of $19 \mathrm{~km} \mathrm{x}$ ${ }_{133} 6.4 \mathrm{~km}$, respectively, and a total displacement of $5 \mathrm{~cm}\left(M_{w}=5.44\right)$ (Figure S6b). The SSE geodetic moment magnitude is strongly constrained, it represents a typical value for a 2-week long SSE [Bürgmann, 2018; Michel et al., 2019] and agrees with an earthquake136 like cubic moment-duration scaling, as reported in Cascadia [Michel et al., 2019; Dal Zilio ${ }_{137}$ et al., 2020] and Mexico [Frank and Brodsky, 2019]. We compute the static stress drop $\Delta \sigma$ following Kanamori and Anderson [1975]:

139

$$
\Delta \sigma=\frac{8}{3 \pi} \frac{G U}{\sqrt{L W}}
$$


142

\section{Analyze of the seismicity during the SSE episode} concealing transient signals.

The average stress drop ranges from $0.03 \mathrm{MPa}$ to $0.32 \mathrm{MPa}$ with $\Delta \sigma=0.115 \mathrm{MPa}$ for our best source model, which is consistent with values from Gao et al. [2012].

We search for recurrent events for the 2004-2019 period using a geodetic template matching [e.g., Rousset et al., 2017] but found no additional events (Section S2 and Figure S7). At the minimum, the recurrence time of such event is about 7-8 years. Our search is however limited by the strain templates allowing to detect only events with nearly similar duration and location as the 2011 SSE. We cannot exclude either that our method failed to detect recurrent events with lower magnitude. Indeed, such signals are below the GPS ambient noise level and frequent rainfall strongly impact strainmeter records, potentially

We analyze the seismicity from days 28 to 43 in 2011 but find no evidence for the occurrence of nonvolcanic tremors or for a temporary increase in seismicity (Figure S8). We also search for repeating earthquakes (REs), as a possible seismological signature of aseismic slip [Uchida and Bürgmann, 2019]. They represent nearly identical asperities that rupture repeatedly under the influence of aseismic slip [e.g., Beeler et al., 2001]. We calculate the cross-correlation coefficients $(c c c)$ of the vertical velocity signals for all earthquake pairs (13 events) recorded by 10 broadband seismic stations distant from 5 to $65 \mathrm{~km}$ from the SSE source (Figure 1a). We filter the 100-Hz sampling signals between 3 and $20 \mathrm{~Hz}$ to suppress microseismic noise and select a cross-correlation window which 
To further characterize the earthquake multiplet, we search for additional events for the 2003-2019 period using waveform template matching. We use event 1 as a template and perform sliding-window cross correlations [Yang et al., 2009] for the same previous stations and same $P$-S phase time-windows. A new event is added to the multiplet if its crosscorrelation coefficient with event 1 is $\geq 0.80$, at minimum, for three stations. We find a total of 11 new events (Table S2 and Figure $3 \mathrm{~b}$ ) with $M_{L}=1.43-2.90$. The multiplet is relocated using the double-difference algorithm HypoDD [Waldhauser and Ellsworth, 2000] with manually picked $P$ - and $S$-wave absolute arrival times and relative cross-correlation delay times. The relative times are determined by cross-correlating all earthquake pairs in the multiplet for both $P$ and $S$ waves using 2 -s length windows beginning $0.1 \mathrm{~s}$ before manual wave picks. All pairs satisfying $c c c \geq 0.80$ are retained for the inversions (85 pairs). To ensure a good constraint on the absolute location of the multiplet, we jointly relocate it with 100 earthquakes selected near and within the SSE source. For these earthquakes, only manually picked $P$ - and $S$ - arrival times are inverted.

As a result, 10 events of the multiplet $\left(M_{L}=1.43-2.76\right)$ are relocated at the depth of about $14.2 \mathrm{~km}$ along a structure dipping about $55^{\circ}$ southeastward (Figure S9), which is 


\section{Influence of static stress changes from the 2003 Chengkung earthquake}


${ }_{204}$ period while some parts of the fault were still creeping at higher rate than during the

${ }_{205}$ preseismic period [Thomas et al., 2014a, 2017]. Given that SSEs are highly sensitive to 206 small stress perturbations (a few kPa) [e.g., Hawthorne and Rubin, 2010], we estimate the ${ }_{207}$ contribution of coseismic and postseismic slip to the SSE occurrence using the Coulomb ${ }_{208}$ failure criterion. If $\delta \sigma_{n}$ and $\delta \tau$ represent respectively the changes in normal stress (tensile

${ }_{211}$ is defined as:

212

$\delta C F F=\delta \tau+\mu^{\prime} \delta \sigma_{n}$

where $\mu^{\prime}$ is the effective friction coefficient, here taken as 0.4 . The fault moves closer to failure if $\delta C F F>0$ and away from failure if $\delta C F F<0 . \delta C F F$ is resolved onto the LVF

Unlike the simple geometry we use to compute the SSE source (justified by the strain data resolution), the fault geometry in the kinematic study followed the local variation of strike of the surface fault trace (to be consistent with the high InSAR spatial resolution) as well as the variation of the dip angle, highlighted by the microseismicity [Thomas et al., 2014a]. Thus, even the projection onto the fault of a smooth displacement field leads to a corresponding rake that varies from one patch to another. It can therefore be misleading to compute the $\delta C F F$ on each individual patch for an imposed rake corresponding to that 
${ }_{225}$ of the SSE. We consequently plot the cumulative displacement as well as the $\delta C F F$ along

${ }_{226}$ the direction of long-term displacement of the LVF. The latter is given by the projection

${ }_{227}$ onto the fault of the long-term displacement of the Central Range relative to the Coastal

${ }_{228}$ Range [Thomas et al., 2014a]. This further allows to discuss if the SSE accommodates

${ }_{229}$ some slip deficit. For the sake of the discussion we also compute the $\delta C F F$ for a patch corresponding to the inferred SSE source $\left(70^{\circ}\right)$.

231

The time-evolution of postseismic slip is modeled using 7 years of geodetic data follow- 
${ }_{247}$ null and negative in the southern and central sections $(\delta C F F \sim-0.5 \mathrm{MPa})$ and positive

${ }_{248}(\delta C F F \sim 0.5 \mathrm{MPa})$ in a limited northermost section. Note that since Coulomb pre-stress

249 changes are only estimated over a 7-year period, they may represent a minimum amount

${ }_{250}$ in the SSE area at the onset of the Chengkung rupture. Finally, for a rake of $70^{\circ}$ on the

${ }_{251}$ patch corresponding to the SSE source, $\delta C F F \sim 0.1-0.2 \mathrm{MPa}$ for all models (Figures 4c ${ }_{252} \& \mathrm{~d}$ and $\left.\mathrm{S} 11 \mathrm{~d}\right)$.

\section{Discussion and concluding remarks}

Coseismic static stress changes are permanent perturbations, with effects lasting from days to years [e.g., Segou and Parsons, 2020], and can therefore explain an extended period ${ }_{256}$ for triggering of aftershocks [King et al., 1994] and SSEs [Hayes et al., 2014; Rolandone ${ }_{257}$ et al., 2018]. Besides, long-lasting stress effects from postseismic deformation can also ${ }_{258}$ play a significant role in promoting delayed rupture [Segou and Parsons, 2018]. The 2017 ${ }_{259} \quad M_{w} 7.1$ Puebla earthquake, Mexico, was likely triggered by postseismic stress changes (up ${ }_{260}$ to $0.1 \mathrm{MPa}$ ) following the $2012 M_{w} 7.5$ Oaxaca event [Segou and Parsons, 2018], while a ${ }_{261}$ combination of postseismic stress changes from the $1964 M_{w} 9.2$ Alaska earthquake and ${ }_{262}$ a 12 year-long SSE possibly promoted the $2018 M_{w} 7.1$ Anchorage earthquake [Segou ${ }_{263}$ and Parsons, 2020].

Here, the 2003 Chengkung earthquake represents the largest event impacting the LVF during the past decades. It generated maximum static Coulomb stress perturbations in ${ }_{267}$ the SSE source region two orders of magnitude larger than any other event (Figure S12). 
We propose that the SSE occurrence has been promoted by the significant Coulomb stress changes $(\delta C F F>0.5-1 \mathrm{MPa}$, about 5-10 times greater than the SSE average stress drop) imparted by a combination of coseismic and postseismic slip from the earthquake, and which persists several years after the mainshock. $\delta C F F$ distribution onto the SSE fault plane reveals a complex pattern (Figures 4 and S11). First, the preseismic stress (1997 to 2003) is essentially negative, with a minimum level similar to the positive coseismic $\delta C F F$. Therefore, it is possible that coseismic Couloumb stress changes could not overwhelm Coulomb pre-stress [e.g., Mildon et al., 2019], which may explain the lack of detected recurrent SSEs right after the mainshock, despite the favourable stress conditions. Conversely, we simply missed an event since no strain data are available within 6 months following the mainshock. Then, the positive coseismic $\delta C F F$ on the southern part of the SSE area may have induced the postseismic slip $(0.4-0.6 \mathrm{~m})$ which in turn generated significant Coulomb stress changes $(\delta C F F>0.5 \mathrm{MPa})$ in the northern section. The latter could be the trigger of the SSE. However, $\delta C F F$ only gives the relative changes of stress for a defined time interval, here the 7-yr preseismic, coseismic and 7-yr postseismic periods.

We now analyze the location of the SSE with respect to the total slip budget using Thomas et al. [2014a] kinematic study. We plot the along-dip variations of slip through time, at the SSE latitude (Figure 4e, area A4) and compare the accumulated slip over 14 years with the total motion of the fault if it had crept at the long term slip rate. We observe a slip deficit between 0 and $16 \mathrm{~km}$ depth, which encompasses the SSE source area. Analyzing the along-strike variation of slip within area A4, we see that for the southern- 
290 most section (column c12, Figure 4f), there is almost no slip deficit unlike for the columns

${ }_{291} \mathrm{c} 13$ to $\mathrm{c} 18$ (Figures S13). Combining $\delta C F F$ and the kinematic analysis we propose the

${ }_{292}$ following scenario: 7 years of afterslip leads to a $\delta C F F>0$ in the north, which triggers

${ }_{293}$ the SSE. It then propagates southward and was further stopped by a stress barrier, i.e.

${ }_{294}$ in an area where all the stress has been released by a combination of coseismic and post-

295 seimic slip. We also observe a slip deficit near the surface (Figure 4e) which is not covered

${ }_{296}$ by the inferred SSE source model. We still know little about the physical mechanisms

${ }_{297}$ and conditions that lead to SSE generation near the surface, where deformation is more

${ }_{298}$ distributed [Thomas et al., 2014b]. Thus, while most of the deformation occurs on the

${ }_{299}$ LVF, we could have failed to detect slip on secondary faults, underestimating the defor-

300 mation near the surface, therefore leading to an apparent slip deficit. This is supported

${ }_{301}$ by the evidence that the shallow creeping portion of the fault (at the depths $<7 \mathrm{~km}$ ) had

302 acted as a rather effective barrier during the 2003 seismic rupture [Thomas et al., 2017].

${ }_{303}$ This means that no remaining stress (therefore no slip deficit) was available to help the

304 rupture propagates to the surface. These observations raise the question of the role of the

${ }_{305}$ SSE transient zone during the 2003 Chengkung rupture. Since insignificant coseismic slip

306 is infer in the transient region (Figures 4 and S13), the latter may have acted as a bar-

${ }_{307}$ rier, limiting the rupture propagation northeastward. Rupture penetration in transient

308 regions being mainly controlled by effective stress differences between "fast" and "slow"

309 slip regions [Lin et al., 2020], further analysis are needed to decipher whether a dominant

310 aseismic slip mode prevails throughout the earthquake cycle for the transient slow slip

311 zone [e.g., Perfettini et al., 2010; Rolandone et al., 2018] (i.e., a permanent barrier), or if 
seismic ruptures can partially or completely penetrate it [e.g., Lin et al., 2020]. Finally, the SSE region also lies in an area of moderate afterslip, suggesting that sections of the LVF experiencing afterslip can also host SSEs [Yarai and Ozawa, 2013; Rolandone et al., 2018].

In addition to triggering aseismic slip, the Chengkung earthquake had also impacted the dynamics of repeater sequences along the LVF, notably halving their recurrence interval [Chen et al., 2020]. During the 2011 SSE, we observe burst-type of nearly identical REs which are events that have extremely short recurrence intervals [Igarashi et al., 2003; Templeton et al., 2008]. However, 8 events (out of 10) of the cluster have $M_{L}<2$ for which distinguishing REs requires high-frequency signal contents and may remain poorly resolved in the seismic waveforms [Uchida and Bürgmann, 2019]. Magnitude limitations as well as uncertainties on the source stress drops and relocations strongly limit our ability 324 to resolve the source overlapping and to assess the source mechanisms of the REs. We therefore propose two possible scenarii based on the previous analysis:

i : Since burst-type REs tend to occur off the major fault planes [Igarashi et al., 2003; Templeton et al., 2008] and Coulomb stress changes caused by the SSE in the RE region 29 is negative $(\delta C F F \sim-0.1 \mathrm{MPa}$ ) (Figure S14), the REs may have occurred spontaneously so with no mechanical link with the SSE. Besides, no SSE is detected during other RE occurrences, and particularly during other burst-type REs (Figure S15), suggesting that aseismic slip is unlikely to be the dominant mechanism of REs in the region [Chen et al., 
33 2009, 2020] (Figure 3d).

334

ii : Conversely, since the fault plane solution of the REs is unknown, our Coulomb 


\section{Acknowledgments}


Sinica, IESAS2386.

\section{References}


CANITANO, GODANO AND THOMAS: SSE ON THE LONGITUDINAL VALLEY FAULT X $\quad 21$

and ocean tidal waveform modeling, J. Geodesy, 92(3), 223-240.

Canitano, A., H. Gonzalez-Huizar, Y. J. Hsu, H. M. Lee, A. T. Linde and S. Sacks (2019), Testing the influence of static and dynamic stress perturbations on the occurrence of a shallow, slow slip event in eastern Taiwan, J. Geophys. Res. Solid Earth, 124(3), 3073-3087, doi:10.1029/2018JB016742.

Chen, K. H., R. J. Rau and J. C. Hu (2009), Variability of repeating earthquake behavior along the Longitudinal Valley fault zone of eastern Taiwan, J. Geophys. Res., 114, B05306, doi:10.1029/2007JB005518.

Chen, Y., K. H. Chen, J. C. Hu and J. C. Lee (2020), Probing the variation in aseismic slip behavior around an active suture zone: observations of repeating earthquakes in Eastern Taiwan, J. Geophys. Res. Solid Earth, 125(5), doi:10.1029/2019JB018561.

Dal Zilio, L., N. Lapusta and J. P. Avouac (2020), Unraveling scaling properties of slowslip events, Geophys. Res. Lett., 47, doi:10.1029/2020GL087477.

Eshelby, J. D. (1957), The determination of the elastic field of an ellipsoid inclusion and related problems, Proc. R. Soc. London A, 241, 376-396.

Fasola, S. L., M. R. Brudzinski, S. G. Holtkamp, S. E. Graham and E. Cabral-Cano (2019), Earthquake swarms and slow slip on a sliver fault in the Mexican subduction zone, Proc. Natl. Acad. Sci. U.S.A., 116(15), 7198-7206.

Frank, W. B. and E. E. Brodsky (2019), Daily measurement of slow slip from low-frequency earthquakes is consistent with ordinary earthquake scaling, Sciences Advances, 5(10), eaaw9386. 
${ }_{418}$ Gao, H., D. A. Schmidt and R. J. Weldon (2012), Scaling relationships of source parameters for slow slip events, Bull. Seismol. Soc. Am., 102(1), 352-360.

${ }_{420}$ Gualandi, A., C. Nichele, E. Serpelloni, L. Chiaraluce, D. Latorre, M. E. Belardinelli and

J. P. Avouac (2017), Aseismic deformation associated with an earthquake swarm in the northern Apennines (Italy), Geophys. Res. Lett., 42, doi:10.1002/2017GL073687.

Hawthorne, J. C. and A. M. Rubin (2010), Tidal modulation of slow slip in Cascadia, J. Geophys. Res., 115, B09406, doi:10.1029/2010JB007502.

Hayes, G. P., K. P. Furlong, H. M. Benz and M. W. Herman (2014), Triggered aseismic slip adjacent to the 6 February $2013 M_{w}$ 8.0 Santa Cruz Islands megathrust earthquake, Earth Planet. Sci. Lett., 388, 265-272.

Herring, T., W. King and S. M. McCluskey (2010), Introduction to GAMIT/GLOBK release 10.4., Mass. Inst. of Technol., Cambridge.

Hsu, Y. J., Y. S. Chang, C. C. Liu, H. M. Lee, A. T. Linde, S. Sacks, G. Kitagawa and Y. G. Chen (2015), Revisiting borehole strain, typhoons, and slow earthquakes using quantitative estimates of precipitation-induced strain changes, J. Geophys. Res. Solid Earth, 120(6), 4556-4571.

Huang, K. C., H. Kao and Y. M. Wu (2000), The determination of $M_{L}-M_{w}$ in Taiwan, in Proceedings of the 8th Annual Meeting of Geophysical Society of China, Taipei City, Taiwan, pp. 193-201.

Igarashi, T., T. Matsuzawa and A. Hasegawa (2003), Repeating earthquakes and interplate aseismic slip in the northeastern Japan subduction zone, J. Geophys. Res., 108(B5), 2249, doi:10.1029/2002JB001920. 
${ }_{440}$ Institute of Earth Sciences, Academia Sinica, Taiwan (1996), Broadband Array in Taiwan for Seismology. Institute of Earth Sciences, Academia Sinica, Taiwan. Other/Seismic Network, doi:10.7914/SN/TW. 
${ }_{462}$ Linde, A. T., M. T. Gladwin, M. J. S. Johnston, R. L. Gwyther and R. G. Bilham (1996), A slow earthquake sequence on the San Andreas fault, Nature, 383, 65-68.

${ }_{464}$ Liu, C. C., A. T. Linde and I. S. Sacks (2009), Slow earthquakes triggered by typhoons, Nature, 459, 833-836.

${ }_{466}$ Michel, S., A. Gualandi and J. P. Avouac (2019), Similar scaling laws for earthquakes and Cascadia slow-slip events, Nature, 574, doi:10.1038/s41586-019-1673-6.

${ }_{468}$ Mildon, Z. K., G. P. Roberts, J. P. Faure Walker and S. Toda (2019), Coulomb pre-stress

${ }_{469}$ and fault bends are ignored yet vital factors for earthquake triggering and hazard, Nat.

470 Commun., 10(2744), doi:https://doi.org/10.1038/s41467-019-10520-6.

${ }_{471}$ Mouyen, M., A. Canitano, B. F. Chao, Y. J. Hsu, P. Steer, L. Longuevergne and J. P. Boy (2017), Typhoon-induced ground deformation, Geophys. Res. Lett., 44(21), 11,004$473 \quad 11,011$.

${ }_{474}$ Murase, M., N. Matta, C. H. Lin, W. S. Chen and N. Koizumi (2013), An episodic creepslip event detected by precise levelling surveys in the central part of the Longitudinal Valley Fault, eastern Taiwan, in 2011-2012, Tectonophysics, 2013, 904-913.

${ }_{477}$ Okada, Y. (1992), Internal deformation due to shear and tensile faults in a half-space,

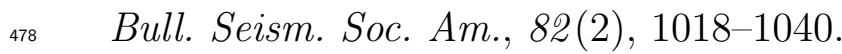

${ }_{479}$ Peng, Z. and J. Gomberg (2010), An integrated perspective of the continuum between earthquakes and slow-slip phenomena, Nat. Geosc., doi:10.1038/NGEO940. Perfettini, H., J. P. Avouac, H. Tavera, A. Kositsky, J. M. Nocquet, F. Bondoux, M. Chlieh, A. Sladen, L. Audin, D. L. Farber and P. Soler (2010), Seismic and aseismic slip on the Central Peru megathrust, Nature, 465, 78-81. 
CANITANO, GODANO AND THOMAS: SSE ON THE LONGITUDINAL VALLEY FAULT X -25

${ }_{484}$ Peyret, M., S. Dominguez, R. Cattin, J. Champenois, M. Leroy and A. Zajac (2011),

${ }_{485}$ Present-day interseismic surface deformation along the Longitudinal Valley, eastern

486

Taiwan, from a PS-InSAR analysis of the ERS satellite archives, J. Geophys. Res., 116, B03402, doi:10.1029/2010JB007898.

Radiguet, M., H. Perfettini, N. Cotte, A. Gualandi, B. Valette, V. Kostoglodov, T. Lhomme, A. Walspersdorf, E. Cabral Cano and M. Campillo (2016), Triggering of the $2014 M_{w} 7.3$ Papanoa earthquake by a slow slip event in Guerrero, Mexico, Nat. Geosc., doi:10.1038/NGEO2817.

Rolandone, F., J. M. Nocquet, P. A. Mothes, P. Jarrin, M. Vallée, N. Cubas, S. Hernandez, M. Plain, S. Vaca and Y. Font (2018), Areas prone to slow slip events impede earthquake rupture propagation and promote afterslip, Sci. Adv., 4, eaao6596.

Rousset, B., M. Campillo, C. Lasserre, W. B. Frank, N. Cotte, A. Walpersdorf, A. Socquet and V. Kostoglodov (2017), A geodetic matched filter search for slow slip with application to the Mexico subduction zone, J. Geophys. Res. Solid Earth, 122, 10,498-10,514.

Sacks, S., S. Suyehiro, D. W. Evertson and Y. Yamagishi (1971), Sacks-Evertson strainmeter, its installation in Japan and some preliminary results concerning strain steps, Pap. Meteorol. Geophys., 22, 195-208.

Segou, M. and T. Parsons (2018), Testing earthquake links in Mexico from 1978 to the $2017 M=8.1$ Chiapas and $M=7.1$ Puebla shocks, Geophys. Res. Lett., 45, 708-714.

Segou, M. and T. Parsons (2020), The role of seismic and slow slip events in triggering the 2018 M7.1 Anchorage earthquake in the Southcentral Alaska subduction zone, Geophys. Res. Lett., doi:10.1029/2019GL086640. 
Templeton, D. C., R. M. Nadeau and R. Bürgmann (2008), Behavior of repeating earthquake sequences in Central California and the implications for subsurface fault creep, Bull. Seismol. Soc. Am., 98(1), 52-65.

Thomas, M. Y., J. P. Avouac, J. Champenois, J. C. Lee and L. C. Kuo (2014a), Spatiotemporal evolution of seismic and aseismic slip on the Longitudinal Valley Fault, Taiwan, J. Geophys. Res., 119(6), 5114-5139.

Thomas, M. Y., J. P. Avouac, J. P. Gratier and J. C. Lee (2014b), Lithological control on the deformation mechanism and the mode of fault slip on the Longitudinal Valley Fault, Taiwan, Tectonophysics, 632, 48-63.

Thomas, M. Y., J. P. Avouac and N. Lapusta (2017), Rate-and-state friction properties of the Longitudinal Valley Fault from kinematic and dynamic modeling of seismic and aseismic slip, J. Geophys. Res., 122, doi:10.1002/2016JB013615.

Toda, S, R. S. Stein, K. Richards-Dinger and S. Bozkurt (2005), Forecasting the evolution of seismicity in southern California: Animations built on earthquake stress transfer, $J$. Geophys. Res., 110, B05S16, doi:10.1029/2004JB003415.

Uchida, N. and R. Bürgmann (2019), Repeating earthquakes, Annu. Rev. Earth Planet Sci., 47, doi:10.1146/annurev-earth-053018-060119.

Vallée, M., J. M. Nocquet, J. Battaglia, Y. Font, M. Segovia, M. Régnier, P. Mothes, P. Jarrin, D. Cisneros, S. Vaca, H. Yepes, X. Martin, N. Béthoux and M. Chlieh (2013), Intense interface seismicity triggered by a shallow slow slip event in the Central Ecuador subduction zone, J. Geophys. Res., 118, 2965-2981. 
${ }_{527}$ Waldhauser, F. and W. L. Ellsworth (2000), A double-difference earthquake location algorithm: method and application to the northern Hayward fault, Bull. Seism. Soc. Am., $90(6)$, 1353-1368.

Wessel, P. and W. H. F. Smith (1998), New, improved version of the Generic Mapping Tools released, Eos Trans. AGU, 79, 579, doi:10.1029/98EO00426.

Wu, Y. M., R. M. Allen and C. F. Wu (2005), Revised $M_{L}$ determination for crustal earthquakes in Taiwan, Bull. Seism. Soc. Am., 95(6), 2517-2524.

Yang, H., L. Zhu and R. Chu (2009), Fault-plane determination of the 18 April 2008 Mount Carmel, Illinois, earthquake by detecting and relocating aftershocks, Bull. Seism. Soc. Am., $99(6), 3413-3420$.

Yarai, H. and S. Ozawa (2013), Quasi-periodic slow slip events in the afterslip area of the 1996 Hyuga-nada earthquakes, Japan, J. Geophys. Res., 118, 2512-2527.

Yu, S. B., H. Y. Chen and L. C. Kuo (1997), Velocity field of GPS stations in the Taiwan area, Tectonophysics, 274, 51-59. 


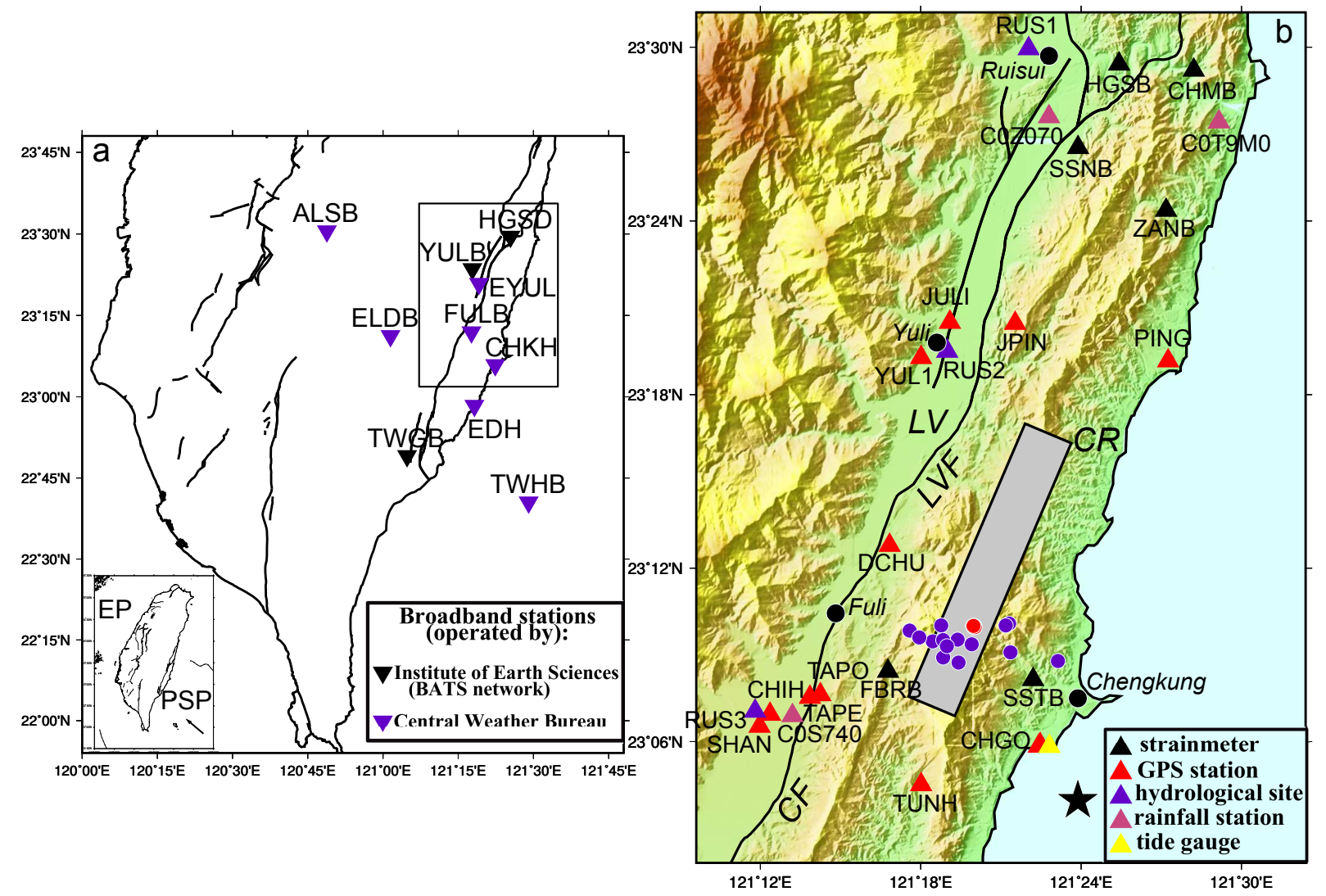

Figure 1. (a) Map of southern Taiwan. Inverted triangles denote broadband seismometers used in this study. (Inset) Geodynamic framework of Taiwan. Black arrow indicates relative motion between Philippine Sea plate (PSP) and Eurasian plate (EP). Black box shows the area in (b). (b) Map of the Longitudinal Valley. Gray rectangle indicates the surface projection of the SSE fault plane. Blue and red dots represent the earthquake multiplet before and after relocation, respectively (Section 4). Black star denotes the Chengkung earthquake epicenter and black dots the main towns. LV: Longitudinal Valley; CR: Coastal Range; LVF: Longitudinal Valley fault; CF: Chihshang fault. 

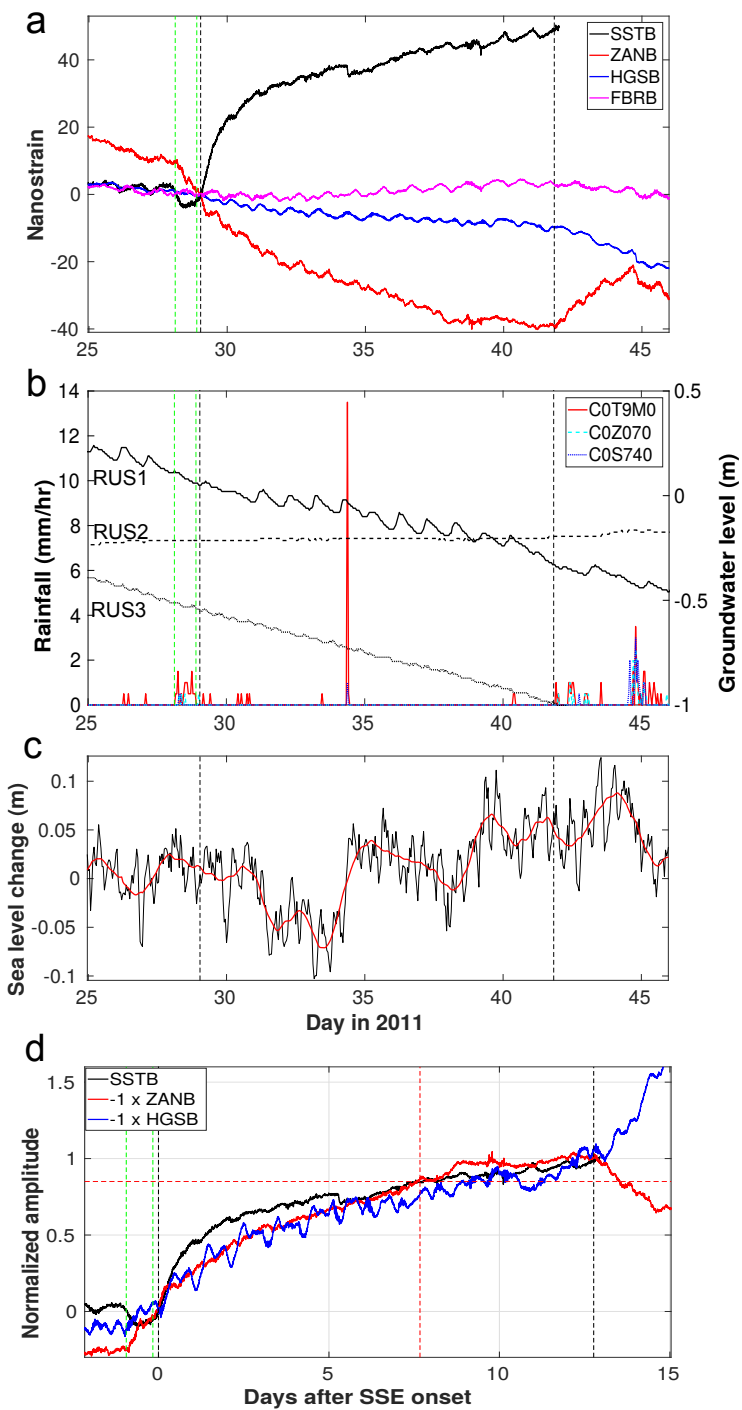

Figure 2. (a) Residual dilatation signals (expansion strain $>0$ ). SSNB experiences a power outage from days 42-47. Vertical black and green dashed lines indicate the SSE episode duration (around days 29.06 to 41.8) and the light rainfall period preceding the SSE, respectively. (b) Hourly rainfall and groundwater level variations (black curves), and (c) detided sea level variations (black curve) and smoothed signal (red curve). (d) Dilatation signals from $01 / 27$ to $02 / 13 / 2011$ (days 27 to 44 ) normalized by the value reached at the end of the SSE episode (ZANB and HGSB are inverted). Vertical red dashed line indicates the timing of repeaters, occurring when $85 \%$ of total aseismic slip was relieved $(4.25 \mathrm{~cm})$ (horizontal red dashed line).

D R A F T

November 6, 2020, 11:55am

D R A F T 

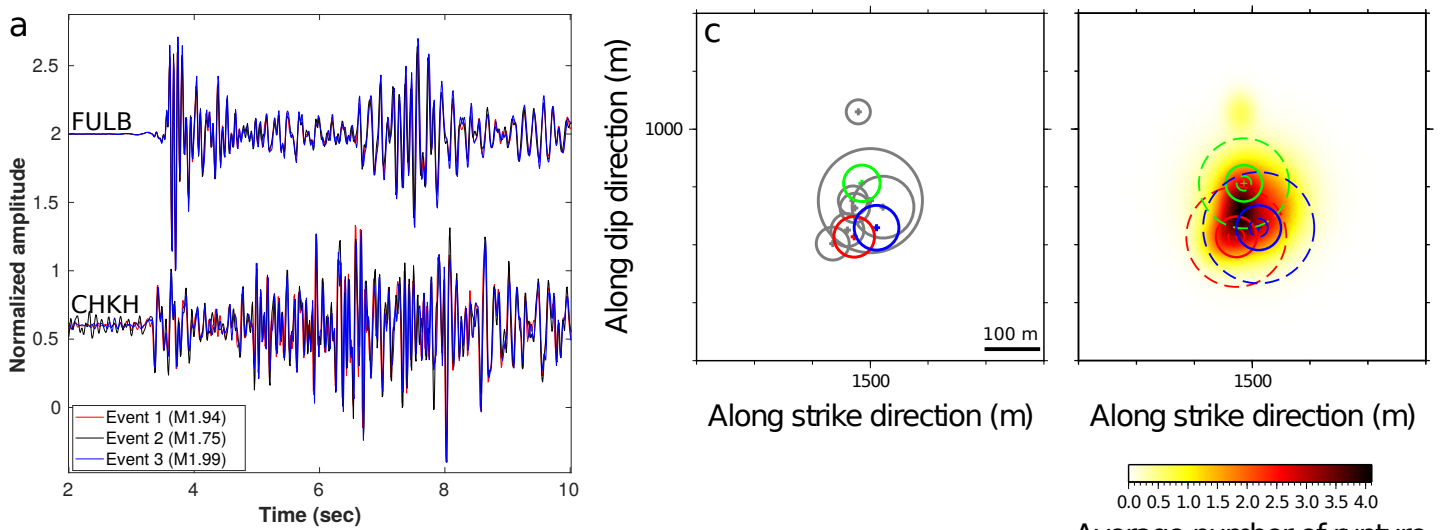

Along strike direction (m)

Along strike direction (m)

0.00 .51 .01 .52 .02 .53 .03 .54 .0 Average number of rupture
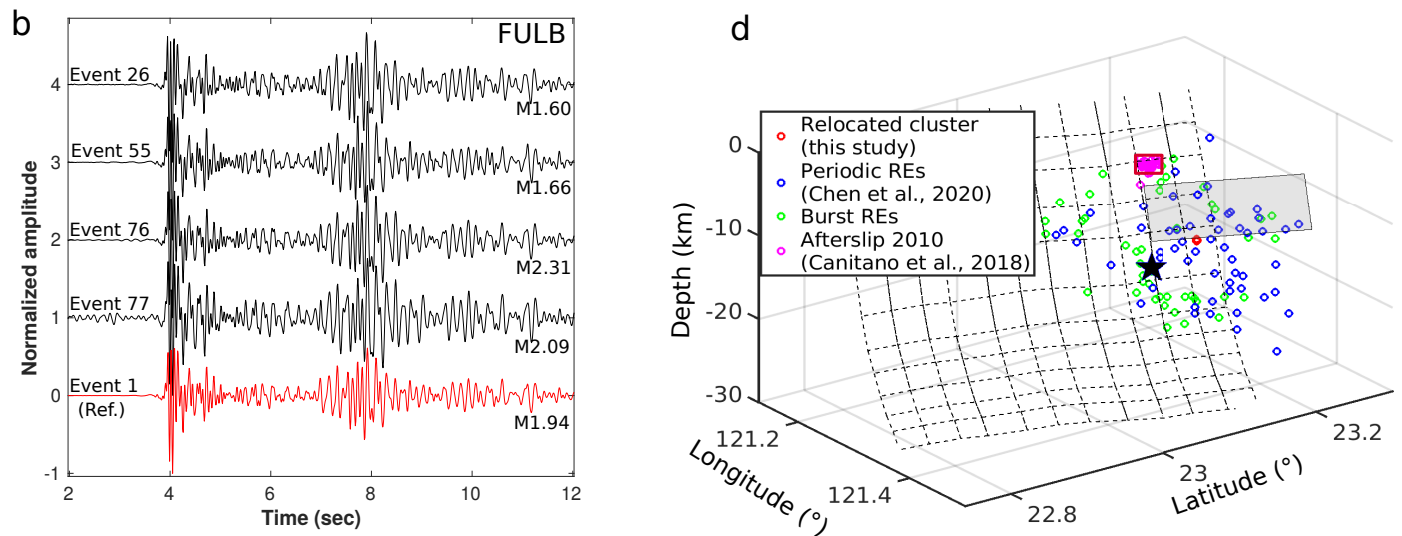

Figure 3. (a) Burst-type REs identified during the SSE episode $(c c c>0.92)$. Multiplets $(c c c>0.90)$ detected during the 2003-2019 period for station FULB using template matching analysis. (c) Projection of the event centroids and rupture surfaces onto the LVF plane. (Left) Mean source rupture radii. Red, green and blue circles denote events 1, 2 and 3 in 2011, respectively. Gray circles are other events of the multiplet. (Right) Mean (plain circle) and extremum source radius uncertainties (dashed circles) for the 2011 events superimposed with the average number of ruptures of the multiplet. (d) Seismic and aseismic processes near the 2003 Chengkung earthquake (black star) source region. Periodic REs and burst-type REs are events with $M_{L} \geq 2$ for the 2000-2011 period (see Chen et al. [2020] for details). Gray and plain red rectangles outline the SSE and afterslip [Canitano et al., 2018a] fault planes, respectively. 

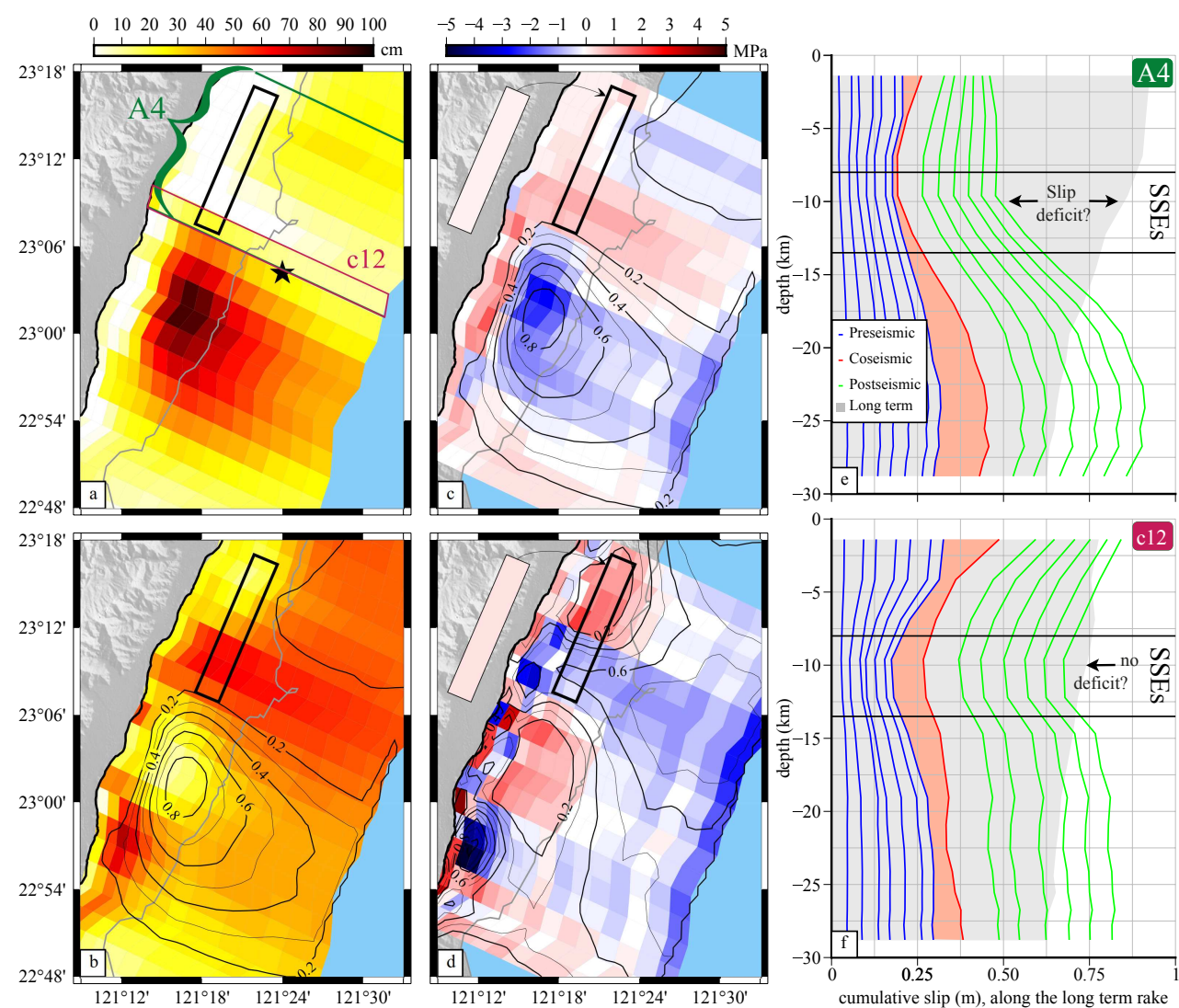

Figure 4. Kinematic slip models of (a) the 2003 Chengkung earthquake and (b) the following 7-year postseismic period (12/2003-11/2010). Static Coulomb stress changes imparted by (c) coseismic and (d) postseismic slip, resolved onto the LVF fault plane. The plane depicted on the side represents $\delta C F F$ computed for a fixed rake of $70^{\circ}$. Black rectangle outlines the SSE rupture area and black star denotes the Chengkung earthquake epicenter. Black curves give the contour lines of the coseismic (b,c) and postseismic (d) slip distribution models (in meter). Cumulative slip along the long-term rake for the A4 area and for the column c12 (see (a)) are given respectively in (e) and (f). For area A4, slip time-series are averaged for patches at the same depth, i.e. we performed 15 times an along-strike average within a swath spanning 7 patches $(3.16 \times 22.12 \mathrm{~km})$. Cumulative slip with depth are plotted with an increment of 1 year for the 7 -yr preseismic (blue) and the 7-yr postseismic (green) periods. Red and grey shading give respectively the coseismic slip and the total motion of the fault if it had crept at the long term slip rate during those D R A F T November 6, 2020, 11:55am 14 years. 